\title{
The Influence of Indomethacin and Guanethidine on Experimental Streptozotocin Diabetic Neuropathy
}

\author{
Douglas W. Zochodne and Lam T. Ho
}

\begin{abstract}
In diabetic animals, reduced endoneurial perfusion and oxygen content have been linked to neuropathic abnormalities and might be amenable to pharmacological manipulation. In streptozotocin-induced diabetic rats, we studied the influence of guanethidine adrenergic sympathectomy, indomethacin treatment and a combined strategy on: serial in vivo motor and sensory conduction, resistance to ischemic conduction failure, in vitro myelinated and unmyelinated conduction, endoneurial perfusion and endoneurial oxygen tension. Unlike previous work diabetic animals had normal endoneurial perfusion but lower endoneurial oxygen tensions after six months of hyperglycemia. Guanethidine worsened sensory conduction despite lower microvascular resistance and an improvement in endoneurial oxygen tension. In contrast, indomethacin improved motor and sensory conduction but not oxygen tension. These studies do not support a linkage between conduction deficits and early endoneurial microangiopathy in experimental diabetes. Indomethacin, or related agents may offer a new therapeutic approach toward diabetic neuropathy through a mechanism independent of the endoneurial microvasculature.
\end{abstract}

RÉSUMÉ: Influence de l'indométhacine et de la quanéthidine sur la neuropathie diabétique expérimentale induite par la streptozotocine. Chez les animaux diabétiques, des diminutions de la perfusion et du contenu en oxygène de l'endonèvre ont été reliées à des anomalies neuropathiques et pourraient être sensibles à des manipulations pharmacologiques. Dans le diabète induit par la streptozotocine chez le rat, nous avons étudié l'influence de la sympathectomie adrénergique par la quanéthidine, le traitement par l'indométhacine et une stratégie combinée sur: la conduction motrice et sensitive sériée in vivo, la résistance au déficit de conduction ischémique, la conduction myélinisée et non-myélinisée in vitro, la perfusion et la tension en oxygène de l'endonèvre. Contrairement aux travaux antérieurs, les animaux diabétiques avaient une perfusion normale de l'endonèvre, mais une tension en oxygène de l'endonèvre plus basse après 6 mois d'hyperglycémie. La guanéthidine empirait la conduction sensitive malgré une résistance microvasculaire plus basse et une amélioration de la tension en oxygène de l'endonèvre. Par contre, l'indométhacine a amélioré la conduction motrice et sensitive sans toutefois améliorer la tension en oxygène. Ces études ne supportent pas l'hypothèse d'un lien entre les déficits de la conduction et la microangiopathie précoce de l'endonèvre dans le diabète expérimental. L'indométhacine ou des agents de cette nature peuvent offrir une approche thérapeutique nouvelle pour la neuropathie diabétique par un mécanisme qui est indépendant de la microvasculature de l'endonèvre.

Can. J. Neurol. Sci. 1992; 19:433-44I

The etiology of diabetic neuropathy remains controversial. Pathological features of human sural nerve biopsies have suggested an ischemic mechanism. ${ }^{1-10}$ This evidence, however, of cause and effect has been indirect and does not address early mechanisms of conduction abnormalities. In experimental models of diabetes direct recordings have identified endoneurial hypoxia." Moreover, hypoxic rearing of animals induces electrophysiological ${ }^{12}$ changes resembling diabetes, and oxygen supplementation or hyperbaric oxygen rearing improves electrophysiological, biochemical and fast axonal transport features of experimental diabetic neuropathy. ${ }^{13-15}$

Evidence for early endoneurial diabetic microangiopathy in animal models includes the finding of lowered nerve blood flow by some, 11 but not all workers. ${ }^{16}$ If hypoxia and oligemia contribute to early neuropathic changes in diabetic animals, then pharmacological enhancement of nerve perfusion and oxygenation should be of benefit. One strategy, guanethidine sympathectomy, does dilate endoneurial microvessels, and increases perfusion in normal rats, ${ }^{17}$ but its influence in diabetes is conflicting. ${ }^{18.19}$ Cyclo-oxygenase inhibitors also might be potentially useful by reducing thromboxane and platelet aggregation in diabetic nerve..$^{20}$ ASA slows the progression of human diabetic retinopathy ${ }^{21}$ and piroxicam retarded loss of sensory potentials in diabetic rats. ${ }^{22}$ It is uncertain if these benefits are a result of improved nerve perfusion with increased oxygenation.

From the Peripheral Nerve Research Laboratory, Queen's University, Kingston (now at University of Calgary)

Received February 21, 1992. Accepted in final form May 27, 1992.

Reprint requests to: Dr. D. Zochodne, Room 182-A, Heritage Medical Research Building, 3330 Hospital Drive N.W., Calgary, Alberta, Canada $\mathrm{T} 2 \mathrm{~N} 4 \mathrm{~N} 1$ 
We studied the effects of guanethidine monosulfate, which induces adrenergic sympathectomy, and indomethacin, a powerful cyclo-oxygenase inhibitor, on experimental streptozotocin ( $S T Z$ ) induced diabetes in rats (ESDN). Guanethidine, indomethacin or both were given to separate groups of rats and compared with both diabetic and nondiabetic controls. To determine the impact of treatment on neuropathy, serial measurements were made of caudal motor and sensory conduction and resistance to ischemic conduction failure (RICF). At an endpoint of 24 weeks of diabetes we studied in vitro myelinated and unmyelinated conduction, endoneurial blood flow (NBF) using hydrogen clearance and endoneurial oxygen tension $\left(\mathrm{PnO}_{2}\right)$. We addressed the following: (i) Is there endoneurial oligemia and hypoxia after six months of experimental diabetes? (ii) Do guanethidine, indomethacin or both improve conduction deficits in diabetes? (iii) If conduction changes occur with treatment do they correlate with improvements in endoneurial oxygenation or perfusion? To assess the consistency of our measurements, three separate groups of non-diabetic animals served as controls.

\section{Materials and Methods}

\section{Animals}

Animals were 100-125 gram (before injection) male Sprague Dawley rats housed in grouped wire cages with free access to rat chow and water. The experimental protocol was reviewed and approved by the Queen's University Animal Care Committee to ensure ethical standards of treatment.

\section{Diabetes}

Animals were injected with a single dose of intraperitoneal streptozotocin (Zanosar, Upjohn; $65 \mathrm{mg} / \mathrm{kg}$ ) in citrate buffer at $\mathrm{pH}$ 4.5. Blood glucose measurements were made 5-7 days after injection and the rats were considered diabetic only if the values were equal to or higher than $16.0 \mathrm{mmol} / \mathrm{L}$ throughout the studies (measured at 1, 16 and 24 weeks). Glucose measurements were made from the ventral caudal vein using a glucometer (AccuChek IIm; Boehringer Mannheim Canada; Dorval, Quebec) and the oxygen rate method (Beckman Glucose Analyzer 2; Beckman Instruments Inc.; Palo Alto, CA).

\section{Treatment Protocols}

There were seven separate experimental arms summarized in Table 1. The non-diabetic control groups included rats given citrate buffer only $(C)$, rats given STZ that did not develop hyperglycemia $>16.0 \mathrm{mmol} / \mathrm{L}(\mathrm{EX})$, and citrate injected rats given indomethacin (CI). All "diabetic" groups (DC, DG, DGI, DI) only included animals with glucose levels $>16.0 \mathrm{mmol} / \mathrm{L}$. The guanethidine sympathectomy protocol was for five days weekly IP guanethidine monosulfate $(48 \mathrm{mg} / \mathrm{kg}$ ) over five weeks starting one week after STZ. After five weeks additional doses were given once weekly. Non-guanethidine treated animals (all other groups) all underwent a similar protocol of a Ringer's solution (composition $\mathrm{Na}^{+} 145 \mathrm{mM} ; \mathrm{Cl}-145 \mathrm{mM} ; \mathrm{K}^{+} 3.5 \mathrm{mM} ; \mathrm{Ca}^{2+} 2.0$ $\mathrm{mM}$; glucose $6.0 \mathrm{mM}$; Hepes $5.0 \mathrm{mM}$ adjusted to $\mathrm{pH} 7.40$ ) IP injections. Indomethacin was given in suspension $(2 \mathrm{mg} / \mathrm{ml}$ indomethacin; $66.7 \%$ sucrose; $0.014 \%$ butyl paraben) at $2 \mathrm{mg} / \mathrm{kg}$ thrice weekly starting one week after STZ for the entire study except in DGI (guanethidine + indomethacin) where it was started at week 6 (to prevent interference with guanethidine action).

\begin{tabular}{cl}
\hline \hline Table 1. Summary of Experimental Groups \\
\hline \hline Group Name & Description \\
\hline C & $\begin{array}{l}\text { Control non-diabetic rats given citrate buffer at } \\
\text { onset of studies } \\
\text { Control rats given STZ but glucose }<16.0 \mathrm{mmol} / \mathrm{L}\end{array}$ \\
EX & $\begin{array}{l}\text { Control non-diabetic rats treated with indomethacin } \\
\text { as below (DI) }\end{array}$ \\
DC & $\begin{array}{l}\text { Untreated STZ diabetic rats (glucose }>16.0 \\
\text { mmol/L) } \\
\text { Diabetic rats treated with guanethidine } 48 \mathrm{mg} / \mathrm{kg} \text { IP } \\
\text { I week after STZ } 5 / 7 \text { days } x 5 \text { weeks then once } \\
\text { weekly until endpoint } \\
\text { Diabetic rats treated with guanethidine and } \\
\text { indomethacin (indomethacin started after } 5 \text { weeks of } \\
\text { guanethidine alone [as in DG]) } \\
\text { Diabetic rats treated with indomethacin at } 2 \mathrm{mg} / \mathrm{kg} \\
\text { by gavage } 3 / 7 \text { days until endpoint }\end{array}$ \\
\hline
\end{tabular}

\section{Electrophysiological Studies}

Electrophysiological studies were conducted 5-7 days after injection of STZ or buffer and again 16 weeks and 24 weeks (endpoint) later. Recordings were conducted with animals anaesthetized using intraperitoneal pentobarbital $(65 \mathrm{mg} / \mathrm{kg}$ ). Measurements were made of sensory (the nerve is mixed motor and sensory but conduction velocity is determined by the faster conducting sensory fibers) caudal, and motor caudal conduction. The techniques have previously been described. ${ }^{23}$ Conduction velocities for two $(80$ and $60 \mathrm{~mm}$ ) recording segments of the caudal sensory nerve were averaged. Subcutaneous near nerve temperature was maintained at $37 \pm 1^{\circ} \mathrm{C}$ with a thermistor probe and temperature control feedback unit (TH8 and TCAT-1A, Sensortek; Clifton, NJ). Signals were recorded on a digital oscilloscope (Nicolet 310; Madison, WI) and stored on microdiskette. Latencies were measured to the onset of the negative deflection of the potential and amplitudes calculated from baseline to peak ( $80 \mathrm{~mm}$ in both caudal nerves). Resistance to ischemic conduction failure (RICF) measurements were made by occluding the arterial supply of caudal mixed fibers with a proximal tail tourniquet inflated above arterial pressure - the time required for a $50 \%$ decline in the amplitude of the mixed nerve action potential (at a distance of $60 \mathrm{~mm}$ ) was determined.

In vitro recordings were made in a perspex chamber with stainless steel recording electrodes separated by $2 \mathrm{~mm}$ intervals. The nerve was placed across the electrodes, fixed in position with denture adhesive then covered in mineral oil maintained at $37^{\circ} \mathrm{C} \pm 1^{\circ} \mathrm{C}$ (as above). The nerve lengths tested did not significantly differ among the groups and ranged between 14 and 20 $\mathrm{mm}$. Stimuli were $0.15 \mathrm{msec}$ in duration and voltage increased to obtain a supramaximal response for myelinated fibers. To study unmyelinated fibers, the duration of the stimulus was increased to $0.80 \mathrm{msec}$ and a supramaximal ' $\mathrm{C}$ ' potential recorded.

\section{Endpoint Preparation (24 weeks)}

The animals were anaesthetized with sodium pentobarbital by intraperitoneal injection $(65 \mathrm{mg} / \mathrm{kg})$. After completion of the last set of electrophysiological recordings, a ventral midline neck incision was made for placement of left carotid intra- 
arterial line (PE-50; Intramedic; Clay Adams, Parsippany, NJ) connected to a pressure transducer (P23ID Gould; Oxnard, CA) and tracheostomy. The animal was then paralyzed using tubocurarine $(1.5 \mathrm{mg} / \mathrm{kg}$ intra-arterial; Sigma Chemical Co.; St. Louis, MO) and ventilated (Rodent ventilator 683; Harvard Bioscience; South Natick, MA) through flowmeters (NO32-416 and N112026; Cole-Parmer; Chicago, III) to permit regulation of inspired gases. The right sural nerve was removed for in vitro conduction recordings. The left sciatic nerve was exposed, covered in mineral oil and the microelectrode inserted through an epineurial window into the endoneurium. A remote reference $\mathrm{KCl}$-agar bridge electrode was inserted subcutaneously and sutured into place. The microelectrode was connected to a microsensor (Microsensor II, Diamond General; Ann Arbor, Mi) for polarization and current detection. The exposed nerve preparation was maintained at $37^{\circ} \mathrm{C}$ throughout using a thermistor probe connected to a control and feedback unit with an infrared heating lamp (as above). Additional doses of pentobarbital $(20 \mathrm{mg} / \mathrm{kg}$ ) and tubocurarine $(0.8 \mathrm{mg} / \mathrm{kg})$ were administered approximately two hourly through the intra-arterial catheter. Continuous print out of mean arterial pressure (MAP) and microsensor current reading were made using two channels of a polygraph recorder (79E, Grass Instruments; Quincy, MA). Arterial blood gas samples were drawn every 30-60 minutes to ensure physiologic stability and the same volume of fluid was replaced with Ringer's solution.

\section{Nerve Blood Flow and Oxygen Tension}

NBF was measured using an endoneurial microelectrode sensitive to hydrogen clearance as previously described." Two clearance curves, when possible, were obtained in each animal and a mean NBF determined. Hydrogen clearance curves were fitted to a mono or biexponential model for calculation of NBF using a least squares regression program (Systat Version 4.1; Evanston, III). $\mathrm{PnO}_{2}$ was measured following the completion of the clearance curves by using the same electrode, polarized at $-0.65 \mathrm{~V}$ and recording at 10 different sampling depths immediately after bubbling the covering mineral oil with $100 \%$ nitrogen. After five measurements, the microelectrode was removed and reinserted at a different site with five further measurements at different depths. The methods were similar to those used by Tuck et al." In our laboratory, previous $\mathrm{PnO}_{2}$ measurements were made without $\mathrm{N}_{2}$ bubbling, giving higher values. Immediately after each set of $\mathrm{PnO}_{2}$ measurements, the electrode was removed from the nerve and placed in a calibration bath maintained at $37^{\circ} \mathrm{C}$ (Diamond General; Ann Arbor, Mi). The microelectrodes were calibrated with bubbled gas mixtures of 0 , 10 , and $25 \% \mathrm{O}_{2}$ and assessed for linearity (Graphpad Instat; San Diego, CA) - experiments without a linear calibration line were discarded. $\mathrm{PnO}_{2}$ was read from the calibration line. MR (microvascular resistance) was calculated as $\mathrm{MAP} / \mathrm{NBF} . \mathrm{PnO}_{2}$ histograms were constructed from pooled data from each animal group $\left(\mathrm{Cl}\right.$ did not have sufficient numbers of $\mathrm{PnO}_{2}$ measurements for analysis).

\section{Data Analysis}

For each serial and endpoint parameter a mean and standard error were determined for all groups. Serial nerve conduction data were also analyzed by determining the difference in each measurement between the first (one week) and final (24 week) values and calculating a mean and standard error for each group. The experimental groups were compared using a one way analysis of variance (ANOVA), and the Student's t test (two tailed unless specified). Statistics were calculated using an IBM 55SX computer (Systat 4.1, Evanston, Ill; Graphpad Instat, San Diego, CA).

\section{RESULTS}

\section{General Observations}

The diabetic animal groups gained less weight than control animals (Table 2). Hyperglycemia was similar in the four diabetic rat groups (DC, DG, DI, DGI) (Table 2). Slightly (not statistically significant) higher glucose levels in EX and $\mathrm{Cl}$ than $\mathrm{C}$ may have been the result of mild STZ effect (without evidence of overt diabetes) in EX and sucrose ingestion (indomethacin suspension) in $\mathrm{Cl}$. Guanethidine treated animals developed ptosis.

\section{Electrophysiological Studies}

Serial in vivo and endpoint in vitro electrophysiological studies were similar in the three non-diabetic control groups (C, EX and $\mathrm{CI}$ ) (Tables 3,4$)$. The untreated diabetic animals (DC) had slowing of conduction velocities ( $\mathrm{CVs}$ ) in sensory caudal fibers (at 16 weeks and 24 weeks; the onset-final $C V$ difference was also reduced in DC), and in sensory sural fibers in vitro (Tables 3, 4 and Figures 1, 3). In the motor caudal territory CVs tended toward lower values at 16 and 24 weeks of diabetes but the reduction was not statistically significant $(24$ week results in Table 3). Diabetes also reduced the amplitude of the compound nerve action potential (CNAP) recorded from the sensory caudal nerve and from myelinated fibers of the sensory sural nerve in vitro (Tables 3, 4 and Figure 4). Unmyelinated fïber CV's tended toward lower values in diabetes but the difference was not statistically significant (Table 4). RICF was longer in diabetic animals (DC) at one and 16 weeks but only a trend in this direction was noted at endpoint (Figure 2).

CVs were significantly lower in sensory caudal fibers and tended toward lower values in motor caudal and in vitro sural recordings with guanethidine treatment (DG) compared to untreated diabetics (DC) (Tables 3,4). The onset-final sensory

Table 2. Weights and Glucose Levels

\begin{tabular}{lcc}
\hline \hline Group (n) & $\begin{array}{c}\text { Final Weight } \\
(\text { grams) }\end{array}$ & $\begin{array}{c}\text { Final Glucose } \\
(\mathbf{m m o l} / \mathbf{L})^{\mathbf{b}}\end{array}$ \\
\hline A/CONTROLS & & \\
C (11) & $600 \pm 24$ & $5.55 \pm 0.45$ \\
EX (16) & $611 \pm 24$ & $7.84 \pm 1.47$ \\
CI (5) & $492 \pm 44$ & $8.87 \pm 1.75$ \\
B/DIABETICS & & \\
DC (14) & $275 \pm 18^{*}$ & $26.3 \pm 1.5^{*}$ \\
DG (7) & $182 \pm 24^{*}$ & $24.3 \pm 0.7^{*}$ \\
DGI (6) & $218 \pm 10^{*}$ & $23.8 \pm 2.2^{*}$ \\
DI (14) & $244 \pm 16^{*}$ & $22.8 \pm 1.1^{*}$ \\
\hline
\end{tabular}

Values are means \pm SEM.

*Significantly different than controls (see ANOVA below).

a ANOVA $p<0.0001 ;$ C, EX vs DC, DG, DGI, DI all $p<0.0001$. b ANOVA $p<0.0001$; C, EX vs DC, DG, DGI, DI all $p<0.0001$. 
Table 3. Final In Vivo Electrophysiological Results

\begin{tabular}{lccr}
\hline \hline (i) Sensory/Mixed Caudal and RICF & & \\
Gensory CV & & \\
Group (n) & $(\mathbf{m})$ & $\begin{array}{c}\text { Mixed Nerve } \\
\text { Amplitude }(\mu \mathbf{V})\end{array}$ & \multicolumn{1}{c}{$\begin{array}{c}\text { RICF } \\
(\mathbf{m i n s})\end{array}$} \\
\hline A/CONTROLS & & & \\
C (11) & $57.3 \pm 1.1$ & $35.2 \pm 2.9$ & $25.8 \pm 1.5$ \\
EX (16) & $57.3 \pm 1.4$ & $30.8 \pm 1.7$ & $24.6 \pm 0.6$ \\
CI (5) & $54.6 \pm 2.2$ & $28.7 \pm 3.0$ & $27.8 \pm 1.0$ \\
B/DIABETICS & & & \\
DC (13) & $52.8 \pm 1.5^{*}$ & $28.7 \pm 3.1^{*}$ & $27.7 \pm 0.8$ \\
DG (7) & $48.1 \pm 2.0^{*}$ & $17.9 \pm 2.7^{*}$ & $26.7 \pm 1.2$ \\
DGI (6) & $46.9 \pm 0.8^{*}$ & $24.8 \pm 2.8^{*}$ & $26.8 \pm 1.5$ \\
DI (14) & $52.2 \pm 1.0^{*}$ & $27.1 \pm 2.3^{*}$ & $28 \pm 1.1$ \\
\hline
\end{tabular}

${ }^{*}$ Significantly different from controls (see ANOVA below).

a ANOVA $p<0.0001 ; C$ vs DC, $p=0.025 ; C$ vs DGI $p=0.0008 ; C$, EX vs DGl, $p<0.001 ; D C$ vs DG, $P=0.044 ; D C$ vs DGI, $p=0.018$ C. EX vs DI, $p=0.01 ;$ DI vs DGI, $p=0.028$.

b ANOVA $p=0.0064 ; C$ vs DC, $p=0.076$; $C$ vs DG $p=0.0007 ; C$ vs DGI, $p=0.031$; $C$ vs DI, $p=0.029$; DC vs DG, $p=0.016$; DG vs DI, $\mathrm{p}=0.032$.

(ii) Motor Caudal

\begin{tabular}{lll} 
Group (n) & Motor CV $(\mathbf{m} / \mathbf{s})^{\mathbf{c}}$ & Motor Amplitude $(\mathbf{m V})$ \\
\hline A/CONTROLS & & \\
C (11) & $44.1 \pm 2.6$ & $2.68 \pm 0.30$ \\
EX (14) & $45.5 \pm 2.2$ & $3.21 \pm 0.41$ \\
CI (5) & $43.1 \pm 2.1$ & $2.97 \pm 0.34$ \\
B/DIABETICS & & \\
DC (12) & $41.8 \pm 2.6$ & $2.54 \pm 0.31$ \\
DG (7) & $40.4 \pm 4.9$ & $1.99 \pm 0.22$ \\
DGI (6) & $38.4 \pm 2.3$ & $1.85 \pm 0.29$ \\
DI (14) & $50.5 \pm 2.6$ & $2.64 \pm 0.24$ \\
\hline
\end{tabular}

Values are means \pm SEM.

c ANOVA $p=0.08 ;$ DI vs DC, DG, $p=0.02 ;$ DGI vs DI, $p=0.013$.
Table 4. In Vitro Electrophysiological results

\begin{tabular}{lcc}
\hline \hline (i) Sensory Sural Myelinated Fibers & \\
Group (n) & CV $(\mathbf{m} / \mathbf{s})^{\mathbf{a}}$ & Amplitude $(\mathbf{m V})^{\mathrm{b}}$ \\
\hline A/CONTROLS & & \\
C (6) & $54.7 \pm 3.7$ & $1.79 \pm 0.57$ \\
EX (10) & $57.0 \pm 1.6$ & $3.10 \pm 0.37$ \\
Cl (4) & $61.5 \pm 6.8$ & $2.03 \pm 0.46$ \\
B/DIABETICS & & \\
DC (6) & $39.0 \pm 4.8^{*}$ & $0.98 \pm 0.34^{*}$ \\
DG (6) & $32.5 \pm 5.5^{*}$ & $0.49 \pm 0.17^{*}$ \\
DGI (5) & $41.8 \pm 4.1^{*}$ & $1.51 \pm 0.79$ \\
DI (12) & $55.2 \pm 3.2$ & $2.76 \pm 0.65$ \\
\hline
\end{tabular}

*Significantly different from controls (see ANOVA below).

a ANOVA $p<0.0001$; C, EX vs DC, DG, all $p<0.03$; C vs DGI, $p=$ 0.069 ; EX vs DGI, $p=0.018$; DI vs DC, $p=0.006$; DI vs DG, DGI both $\mathrm{p}<0.03$.

b ANOVA $p=0.019 ;$ EX vs DC, $p=0.018$; EX vs DG, $p=0.005 ; D C$ vs DI, $p=0.033$; DG vs DI, $p=0.009$.

(ii) Sensory Sural Unmyelinated Fibers

\begin{tabular}{lcc} 
Group (n) & $\mathbf{C V}(\mathbf{m} / \mathbf{s})$ & Amplitude $(\mu \mathbf{V})$ \\
\hline A/CONTROLS & & \\
C (3) & $0.96 \pm 0.04$ & $37.5 \pm 16.0$ \\
EX (7) & $0.96 \pm 0.09$ & $59.2 \pm 11.8$ \\
B/DIABETICS & & \\
DC (4) & $0.87 \pm 0.07$ & $39.3 \pm 16.1$ \\
DGI (2) & $0.64 \pm 0.04$ & $13.7 \pm 4.7$ \\
DI (10) & $0.96 \pm 0.05$ & $82.2 \pm 11.7$ \\
\hline
\end{tabular}

Values are means \pm SEM.

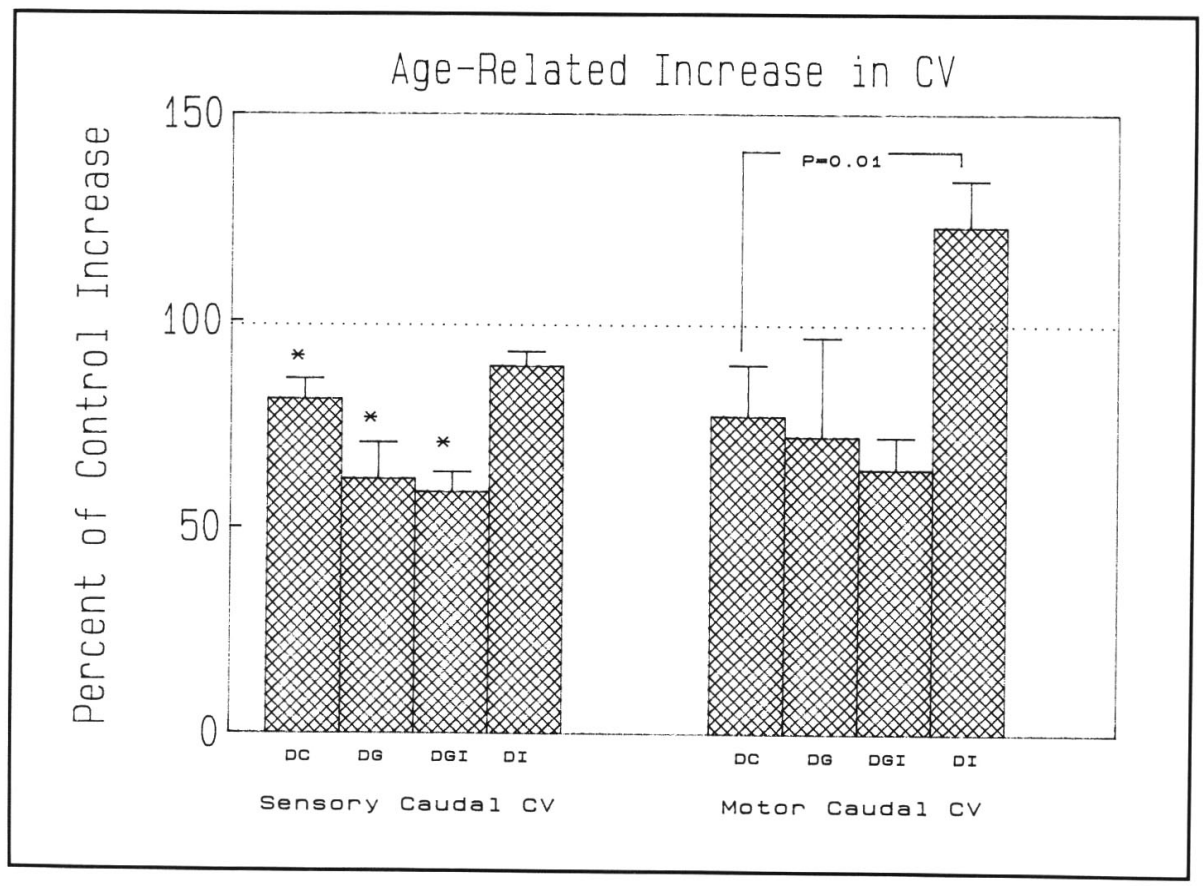

Figure I - The maturational increase (onset-final) of sensory and motor caudal CV as a percentage of control (Group C) values. In sensory fibers. the increase was reduced in all diabetics except those treated with indomethacin alone (DI). Guanethidine further reduced the change. In motor fibers, the increase was greater in diabetics treated with indomethacin $(D I)$ than those untreated $(D C)$. I Significantly different than controls]. 
caudal CV change was lower in DG than DC (Figure 1). Guanethidine with or without indomethacin failed to improve any CVs or amplitude ening except RICF (F at endpoint in the $\mathrm{DC}$

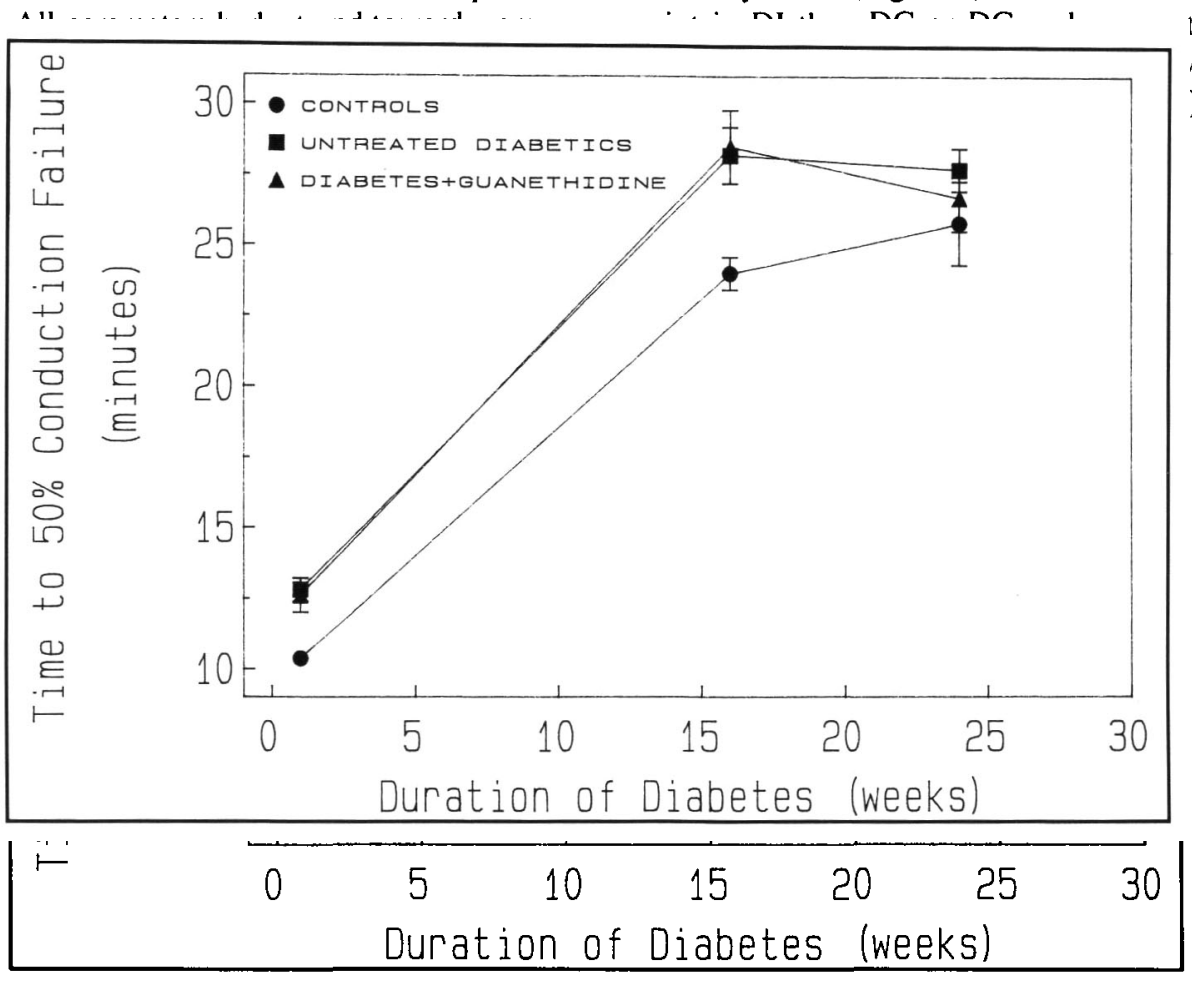

final CV change was greater in DI because its onset CV was significantly lower (Figure 1). Motor caudal CV was higher at endstatistically different as noted in the onset). Indomethacin treat-

Figure 2 - Serial measurements of RICF (resistance to ischemic conduction failure). RICF was statistically higher at one and 16 weeks of diabetes compared to controls (Group Cillustrated). There was a trend toward RICF improvement with guanethidine, but not indomethacin.

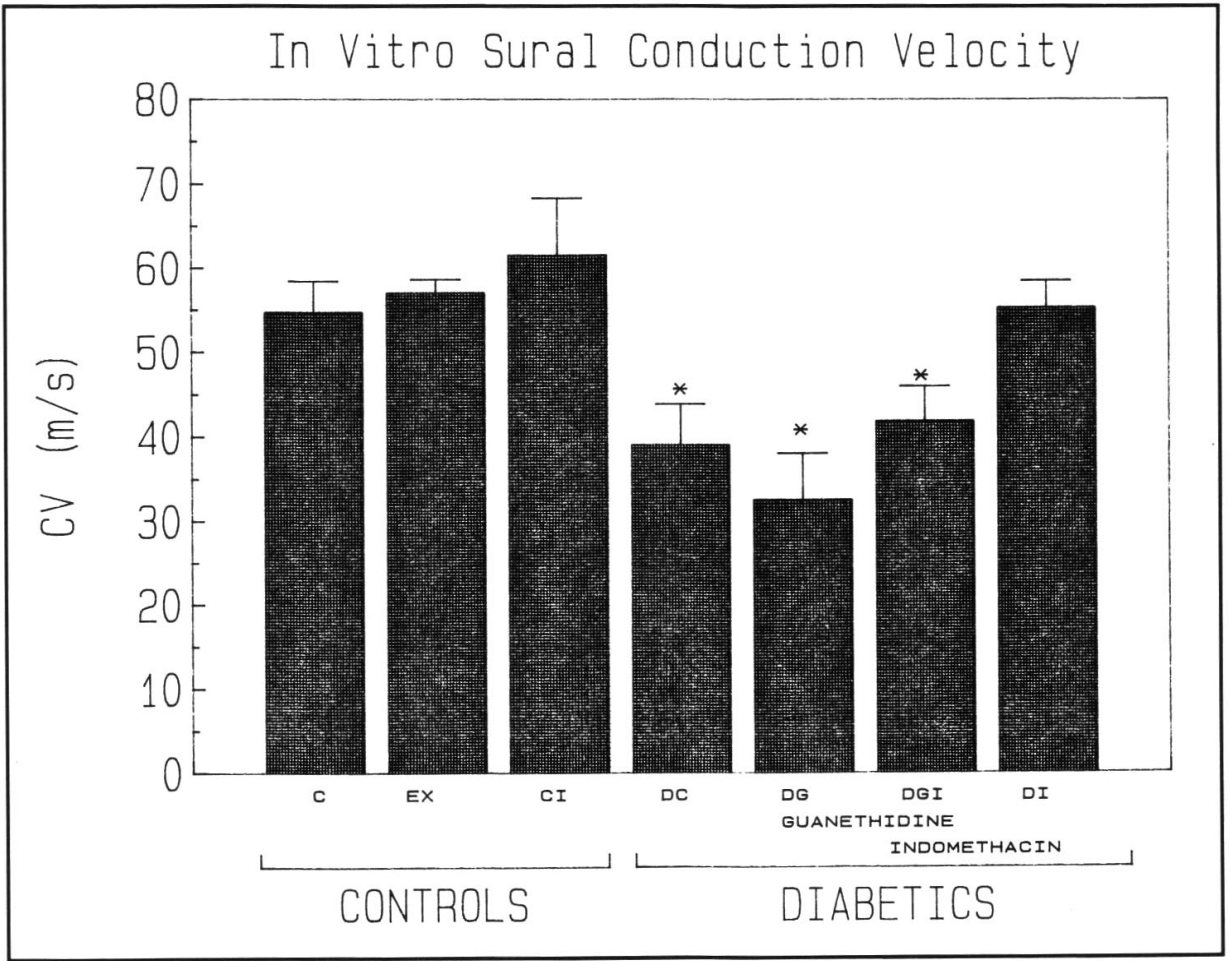

Figure 3 - Sensory sural in vitro conduction velocities were comparable among the control (C, EX, CI) groups but reduced by diabetes. Indomethacin normalized CV. [*Significantly different than controls]. 


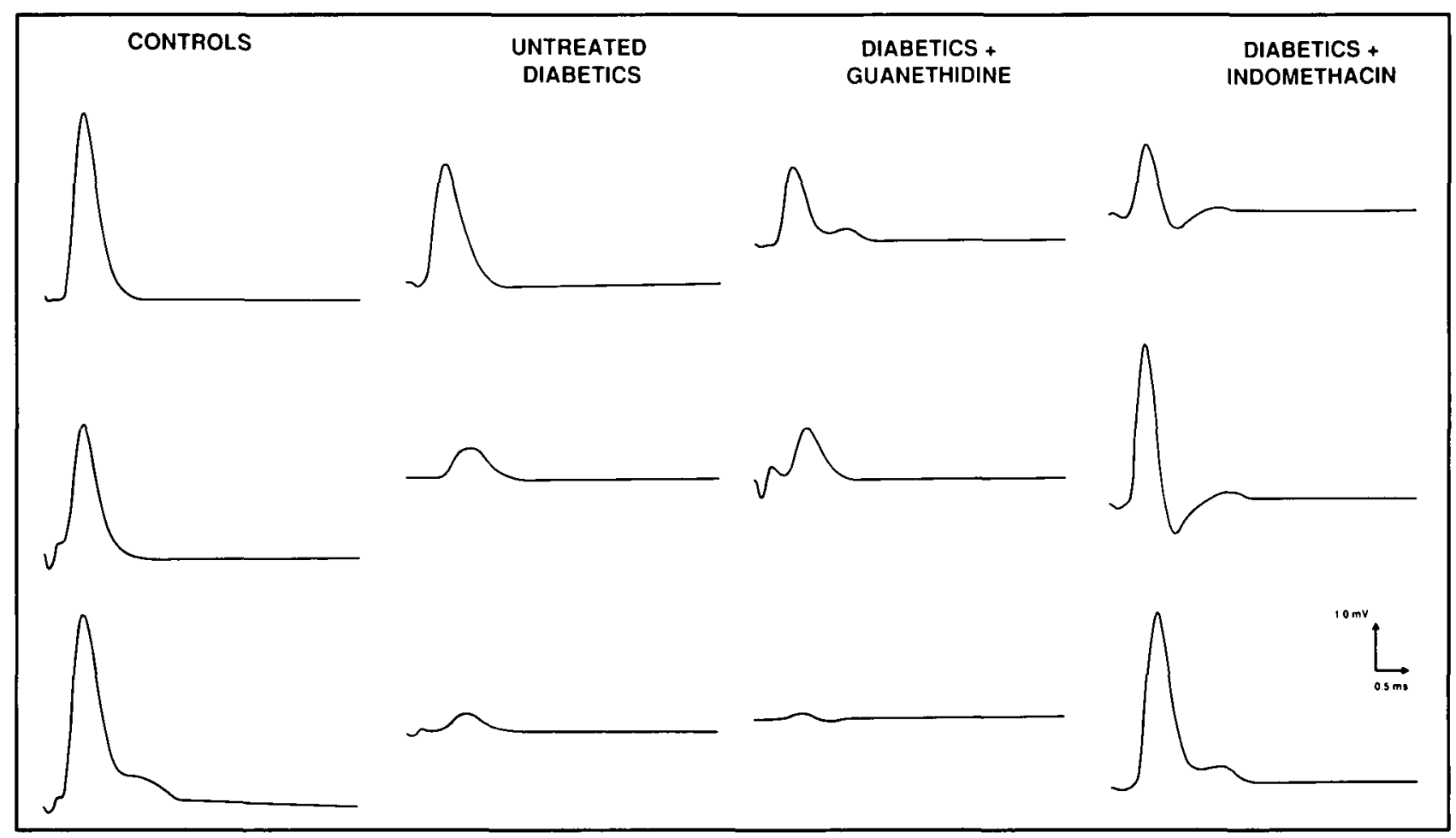

Figure 4-Sensory sural in vitro CNAP's from myelinated fibers.

ment (DI) improved in vitro $\mathrm{CV}$ and CNAPs of myelinated fibers (Table 4, Figures 3,4). A similar trend in unmyelinated fibers was not statistically significant.

\section{Nerve Blood Flow and Oxygen Tension}

NBF and $\mathrm{PnO}_{2}$ were comparable among the non-diabetic control groups including the percentage of $\mathrm{PnO}_{2}$ measurements below 15 torr (Tables 5, 6 and Figure 5). $\mathrm{PnO}_{2}$ values were lower than our previous results because of a change in technique (see above) but comparable to published data from other groups. ${ }^{11.24}$ Histograms were constructed from the following numbers of $\mathrm{PnO}_{2}$ measurements: C-105; EX-135; DC-115; DG-55; DGI-65; DI- 130.

Diabetes did not lower NBF or increase MR (Table 5 and Figure 5). $\mathrm{PnO}_{2}$ histograms were shifted toward lower values in untreated diabetic animals (DC) (Figure 6). The percentage of torr values below 15 torr was lower in DC and DI compared with EX alone or combined control data (since $\mathrm{C}$ and EX conduction data were comparable) from $\mathrm{C}$ and EX (Table 6). DG and DGI groups had values that were comparable to controls. NBF was statistically higher in DI than control groups, but microvascular resistance was significantly reduced only in DG compared to controls (Table 5). MAP was lower than controls in DC and DG, but not DI. Guanethidine lowered MAP yet further in diabetic animals.

\section{Discussion}

The major findings from this study were: (i) diabetes slowed in vivo and in vitro sensory $\mathrm{CV}$, lowered CNAP amplitudes and increased RICF; (ii) diabetes shifted $\mathrm{PnO}_{2}$ toward lower values but did not lower NBF; (iii) guanethidine treatment lowered MAP, but worsened sensory caudal $\mathrm{CV}$ despite improved microvascular resistance and oxygenation; (iv) indomethacin improved sensory caudal, motor caudal and sural conduction (and reduced hypotension) without improving endoneurial microvascular resistance or oxygenation.

Our results were unexpected. We were unable to identify endoneurial oligemia or elevated microvascular resistance in any of our untreated diabetic animals despite using the method of hydrogen clearance, as in other work. "We have not identified a technical explanation for these results because identical techniques, in our previous work, have identified changes in endoneurial perfusion induced by pharmacological manipulations. ${ }^{25}$ All animals had hyperglycemia (at levels higher than most human diabetic patients) for a longer evaluation time than other work (6 months), in vivo and in vitro evidence of neuropathy, and other features of untreated diabetes such as weight loss and cataracts. We studied large numbers of animals (and used three control groups to gauge technical reliability) in each experimental arm to discern small changes but did not observe a subgroup of diabetic animals with lowered NBF. Analysis of the separate control groups convinced us that our results were internally consistent and comparable to previously published data. ${ }^{26-28}$ In particular, EX served as a useful STZ-treated control group that did not develop significant hyperglycemia, cataracts or conduction deficits. The results also support previous work in our laboratory ${ }^{18}$ that failed to identify oligemia in young diabetic rats after 6 or 16 weeks of diabetes. It is unlikely that transient oligemia, undetected by this work, would account for continuing neuropathic deficits. In support of our findings, not all investigators have identified nerve oligemia in diabetes, ${ }^{16}$ and some reports of lowered blood flow have used methods that may be less reliable. ${ }^{29-30}$ Indeed, in one of these studies, microvessels had a paradoxically larger luminal area with untreated dia- 
betes.$^{30}$ In another, ${ }^{29}$ control values of NBF were lower than those of other reports. Morphological changes in endoneurial microvessels from ESDN have been unimpressive in some studies. ${ }^{31}$ One important difference between our animals and those of Tuck et al." was that we induced diabetes in younger rats, but kept them diabetic longer ( 6 months versus 4 months). It is uncertain how this difference would influence the results.

In this and previous work using younger animals studied at earlier time points, we confirmed the finding of lowered

\begin{tabular}{|c|c|c|c|}
\hline Group (n) & $\begin{array}{c}\mathrm{NBF}^{\mathrm{a}} \\
(\mathrm{ml} / \mathbf{1 0 0 \mathrm { g } / \mathrm { min }})\end{array}$ & $\begin{array}{l}\text { NBF (Composite })^{\mathrm{b}} \\
(\mathrm{ml} / 100 \mathrm{~g} / \mathrm{min})\end{array}$ & $\begin{array}{c}\mathrm{MRc}^{\mathrm{c}} \\
\left(\mathrm{mmHg} \mathrm{mogg}^{*} 100\right. \\
\mathrm{min} / \mathrm{ml})\end{array}$ \\
\hline \multicolumn{4}{|c|}{ A/CONTROLS } \\
\hline$C(11)$ & $16.8 \pm 1.4$ & $24.7 \pm 3.2$ & $8.54 \pm 1.15$ \\
\hline $\operatorname{EX}(16)$ & $15.1 \pm 0.9$ & $28.8 \pm 5.0$ & $8.37 \pm 0.49$ \\
\hline $\mathrm{CI}(5)$ & $14.4 \pm 1.7$ & $23.6 \pm 5.8$ & $8.87 \pm 1.13$ \\
\hline \multicolumn{4}{|c|}{ B/DIABETICS } \\
\hline DC (14) & $16.6 \pm 0.9$ & $26.7 \pm 2.6$ & $7.36 \pm 0.61$ \\
\hline $\mathrm{DG}(7)$ & $19.0 \pm 2.0$ & $37.6 \pm 7.8$ & $5.68 \pm 0.71^{*}$ \\
\hline DGI (6) & $20.3 \pm 3.2$ & $30.7 \pm 3.3$ & $5.93 \pm 0.86$ \\
\hline DI (14) & $20.9 \pm 1.7^{*}$ & $39.3 \pm 4.0$ & $6.68 \pm 0.63$ \\
\hline
\end{tabular}

Values are means $\pm S E M$.

"Significantly different from controls (see ANOVA below).

a ANOVA $p=0.024$; DI vs C, EX, CI, DC all $p<0.05$; EX vs DGI, $p=$ 0.04 .

b ANOVA $p=N S ; C$ vs DI, $p=0.029 ; D C$ vs DI, $p=0.035$

c ANOVA $p=0.058$; $C$ vs DG, $p=0.031$; $E X, C$ vs DGI, $p=0.058$; EX vs DG, $p=0.027 ; C l$ vs DG, $p=0.054$. endoneurial oxygen tension in ESDN, also noted in human diabetic neuropathy. ${ }^{32}$ Normal blood flow measurements are not incompatible with endoneurial hypoxia because hydrogen clearance may not require microcirculatory transit of RBCs. Normally, at microvessel bifurcations, some degree of plasma "skimming" occurs. ${ }^{33}$ Rheological changes in diabetic RBCs could result in reduced oxygen delivery to nerve because nondeformable RBCs may have had difficulty negotiating the endoneurial microcirculation unlike "skimmed" plasma. This hypothesis is untested, but a rheological explanation of human diabetic neuropathy has been considered. ${ }^{34}$ Impaired oxygen

Table 6. Endoneurial Oxygen Content, Arterial Oxygen Content, Mean Arterial Pressure

\begin{tabular}{|c|c|c|c|}
\hline Group (n) & $\% \mathrm{PnO}_{2}<15$ Torr $^{\mathrm{a}}$ & $\mathrm{PA0}_{2}$ Torr & $\begin{array}{c}\text { MAPb } \\
(\mathbf{m m H g})\end{array}$ \\
\hline \multicolumn{4}{|l|}{ A/CONTROLS } \\
\hline$C(11)$ & $24.0 \pm 9.7$ & $153 \pm 9$ & $125 \pm 2$ \\
\hline EX (15) & $13.2 \pm 7.1$ & $148 \pm 7$ & $122 \pm 3$ \\
\hline $\mathrm{C}+\mathrm{EX}$ (combined)(26) & $16.8 \pm 5.5$ & & \\
\hline \multicolumn{4}{|l|}{ B/DIABETICS } \\
\hline DC $(15)$ & $39.1 \pm 10.6$ & $147 \pm 6$ & $113 \pm 5$ \\
\hline DG (7) & $12.9 \pm 5.2$ & $185 \pm 18$ & $101 \pm 8$ \\
\hline DGI (7) & $28.6 \pm 13.0$ & $164 \pm 4$ & $105 \pm 3$ \\
\hline DI (15) & $40.0 \pm 8.8$ & $172 \pm 4$ & $118 \pm 3$ \\
\hline
\end{tabular}

Values are means $\pm S E M$.

a ANOVA $p=0.09$; EX vs DC, $p=0.031$; EX vs DI, $p=0.029 ; C+E X$ vs DC, $p=0.034 ; D C$ vs DG, $p=0.08 ; C+E X$ vs $D I, p=0.03$.

b ANOVA $p=0.003 ; C$ vs DC, $p=0.057$; $E X$ vs $D C, p=0.067 ; C$, EX vs DG, $p=0.003 ; \mathrm{DC}$ vs DG, $p=0.067$.

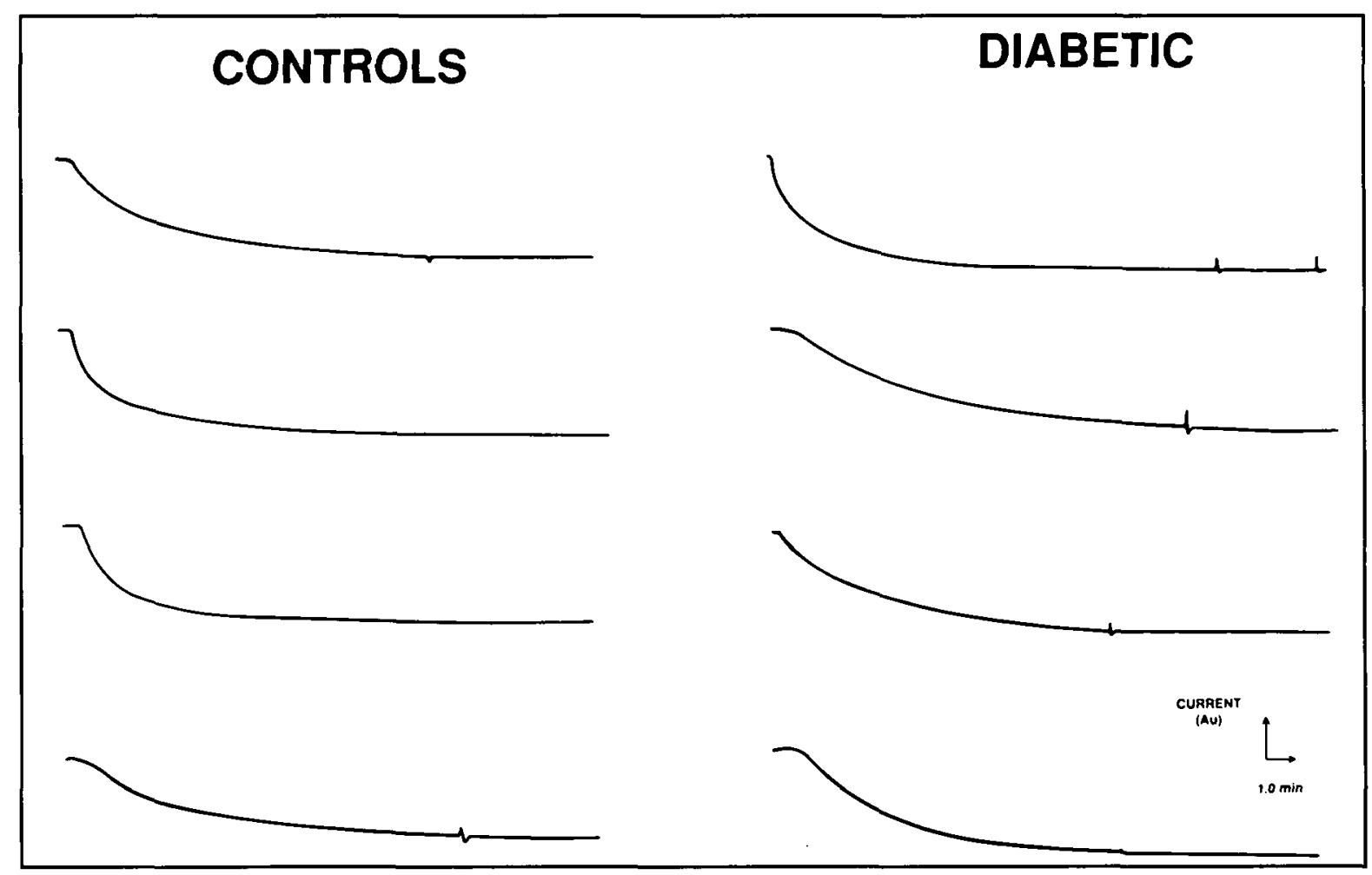

Figure 5-Hydrogen clearance curves from control and diabetic animals. The washout slopes are unchanged by diabetes. 


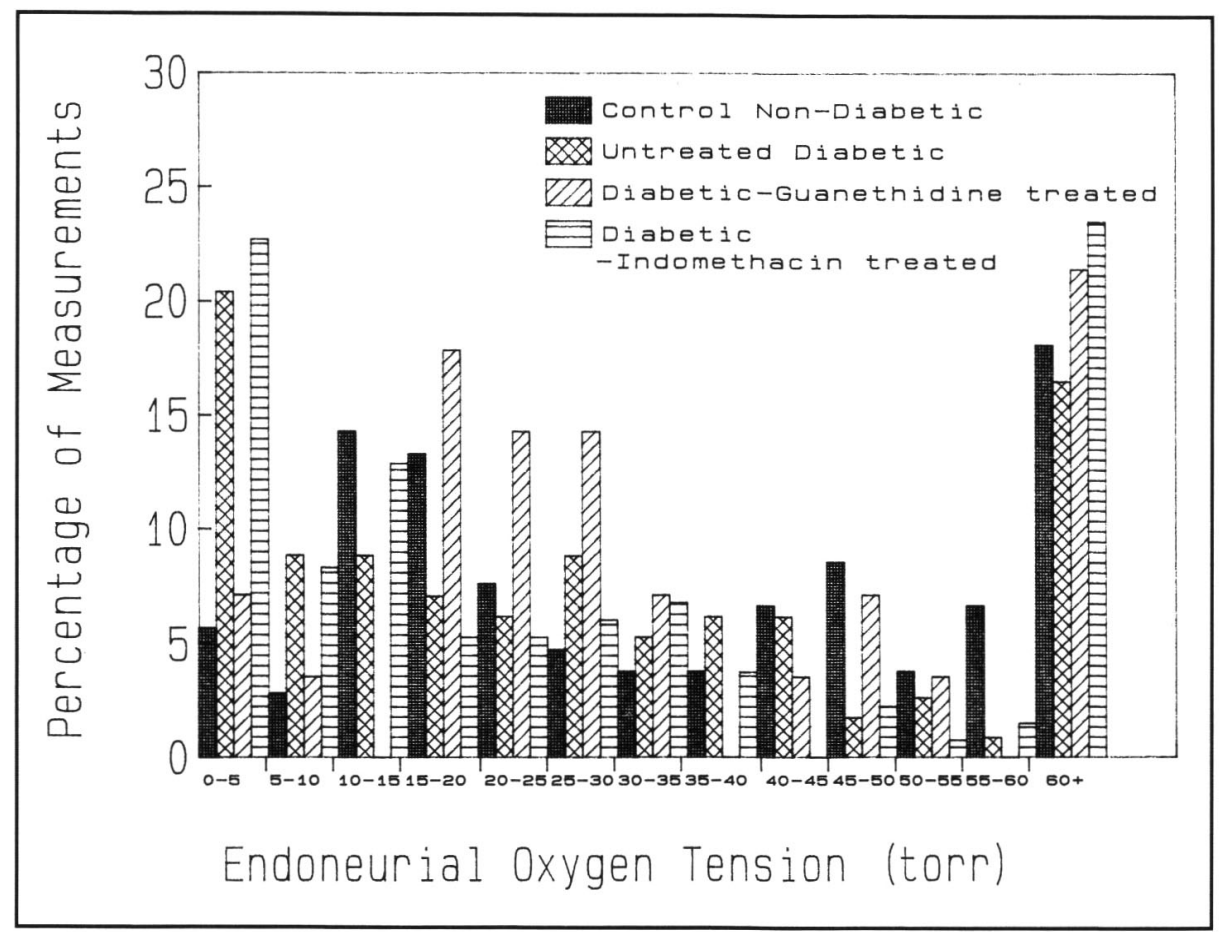

Figure 6 - Oxygen tension histogram. Control animals are from Group C. Untreated diabetic animals have a shift of tensions to lower values. Guanethidine, but not indomethacin improved the oxygen tension profile.

release from hemoglobin is an alternative explanation of our results. ${ }^{35}$ Finally, it is possible that our $\mathrm{PnO}_{2}$ measurements may still reflect subtle microangiopathy missed by hydrogen clearance.

Our work fails to link changes in nerve conduction to nerve oxygenation. Worsened indices of conduction in guanethidinetreated animals were associated with lower microvascular resistance and better endoneurial oxygenation. In contrast, indomethacin improved these indices, but did not alter oxygenation. RICF changed independently of other indices of nerve conduction indicating that it may be a less useful index of pathology. RICF varies with the degree of hyperglycemia ${ }^{36}$ but also may rise with chronic hypoxia in animals or humans. ${ }^{37-38}$ Oxygen supplementation or hyperbaric oxygen treatment in published work, also lowered RICF, and yielded other benefits. ${ }^{13-14}$ Our results likely do not exclude an etiological role for endoneurial hypoxia in ESDN, ${ }^{39}$ but indicate that other factors have an important influence on neuropathic indices.

Guanethidine had no influence on somatic conduction in normal animals from previous work, ${ }^{23}$ but we did not include a further non-diabetic guanethidine-treated control group in this work. Histologic work has also confirmed the apparent specificity ${ }^{40}$ of guanethidine for adrenergic autonomic fibers. One might hypothesize that increased delivery of sorbitol or glycosylated protein to nerve from guanethidine-related microvessel dilatation could worsen ESDN, but we cannot exclude a direct toxic action of guanethidine on diabetic somatic nerves. Indomethacin is a powerful cyclo-oxygenase inhibitor (and was chosen for this reason), but also inhibits aldose reductase ${ }^{41-42}$ Aldose reductase inhibition (ARI) improves ESDN, ${ }^{43-44}$ but by an uncertain mechanism. Indomethacin's benefit without influence on oxygenation, may be evidence that its action (and perhaps that of piroxicam) is through ARI action, though this question will require appropriate tissue sampling for evidence of an ARI effect. Enhanced flux of sugar alcohols into nerve, blocked by ARIs may induce neuropathy by depleting nerve of myo-inositol ${ }^{45}$ or increasing non-enzymatic glycosylation of nerve proteins. ${ }^{46}$

The possible role of non-steroidal anti-inflammatory agents such as piroxicam and indomethacin in the treatment of human diabetic neuropathy requires exploration. Long experience with these agents in treating other conditions may make them easier to evaluate than novel aldose reductase inhibitors.

\section{AbBreviations}

ARI Aldose reductase inhibitor

C, CI, DC, DG, DGI, DI, EX

Experimental groups (See Table 1)

CNAP Compound nerve action potential

CV Conduction velocity

ESDN Experimental STZ-induced diabetic neuropathy

MAP Mean arterial pressure

MR Microvascular (endoneurial) resistance

NBF Nerve blood flow

$\mathrm{PnO}_{2} \quad$ Endoneurial oxygen tension

RICF Resistance to ischemic conduction failure

STZ Streptozotocin

\section{ACKNOWLEDGEMENTS}

Mrs. Lisa Fregeau provided excellent secretarial assistance. Funding support was provided by the Medical Research Council of Canada, Muscular Dystrophy Association of Canada, Canadian Diabetes Association, and Queen's University intramural funds (Botterell Award, 
Principal's Development Fund Category B and Research Initiation Award). Ethicon Canada provided suture material. Dr. Phillip Low kindly facilitated construction of an in vitro nerve conduction chamber. Dr. Zochodne is a recipient of a Career Scientist Award from the Ontario Ministry of Health. The results and conclusions are those of the authors and no official endorsement by the Ministry is intended or should be inferred.

\section{REFERENCES}

1. Dyck PJ, Karnes JL, O'Brien P, Okazaki H, Lais A, et al. The spatial distribution of fiber loss in diabetic polyneuropathy suggests ischemia. Ann Neurol 1986; 19: 440-449.

2. Dyck PJ, Lais A, Karnes JL, O'Brien P, Rizza R. Fiber loss is primary and multifocal in sural nerves in diabetic polyneuropathy. Ann Neurol 1986; 19: 425-439.

3. Johnson PC, Doll SC, Cromey DW. Pathogenesis of diabetic neuropathy. Ann Neurol 1986; 19:450-457.

4. Fagerberg S-E. Diabetic neuropathy: a clinical and histological study on the significance of vascular affections. Acta Medica Scand 1959; 164 (Suppl 345): 1-81.

5. Malik RA, Newrick PG, Sharma AK, Jennings A, Ah-Shee AK, et al. Microangiopathy in human diabetic neuropathy: relationship between capillary abnormalities and the severity of neuropathy. Diabetologia 1989; 32: 92-102.

6. Bischoff A. Die Ultrastrucktur peripherer Nerven bei der diabetischen Neuropathie. Deutsche Gecsellschaft fur Innere Medizin 1967; 18: 1138-1141.

7. Dyck PJ, Hansen S, Karnes J, O'Brien P, Yasuda H, et al. Capillary number and percentage closed in human diabetic sural nerve. Proc Nat Acad Sci (USA) 1985; 82: 2513-2517.

8. Timperley WR, Boulton AJM, Davies-Jones GAB, Jarratt JA, Ward JD. Small vessel disease in progressive diabetic neuropathy associated with good metabolic control. J Clin Pathol 1985; 38: 1030-1038.

9. Williams E, Timperly WR, Ward JD, Duckworth T. Electron microscopical studies of vessels in diabetic peripheral neuropathy. J Clin Pathol 1980; 33: 462-470.

10. Yasuda H. Dyck PJ. Abnormalities of endoneurial microvessels and sural nerve pathology in diabetic neuropathy. Neurology 1987; 37: $20-28$

11. Tuck RR, Schmelzer JD, Low PA. Endoneurial blood flow and oxygen tension in the sciatic nerves of rats with experimental diabetic neuropathy. Brain 1984; 107: 935-950.

12. Low PA, Schmelzer JD, Ward KK, Yao JK. Experimental chronic hypoxic neuropathy: relevance to diabetic neuropathy. Am J Physiol 1986; 250: E94-E99.

13. Low PA, Tuck RR, Dyck PJ, Schmelzer JD, Yao JK. Prevention of some electrophysiologic and biochemical abnormalities with oxygen supplementation in experimental diabetic neuropathy. Pro Nat Acad Sci 1984; 81: 6894-6898.

14. Low PA, Schmelzer JD, Ward KK, Curran GL, Poduslo JF. Effect of hyperbaric oxygenation on normal and chronic streptozotocin diabetic peripheral nerves. Exp Neurol 1988; 99: 201-212.

15. Zollman P, Sahenk Z, Low PA. The effects of hyperbaric oxygenation on fast axonal transport in streptozotocin-induced diabetes. Neurology 1990; 40 (Suppl 1): 124

16. Pugliese G, Tilton RG, Speedy A, et al. Effects of very mild versus overt diabetes on vascular haemodynamics and barrier function in rats. Diabetologia $1989 ; 32: 845-857$.

17. Zochodne DW, Huang Z, Ward K, Low PA. Guanethidine-induced adrenergic sympathectomy augments endoneurial perfusion and lowers endoneurial microvascular resistance. Brain Res 1990; 519: 112-117.

18. Zochodne DW, Ho LT. Normal blood flow but lower oxygen tension in diabetes of young rats: microenvironment and the influence of sympathectomy. Can J Physiol Pharmacol (in press).

19. Cameron NE, Cotter MA, Low PA. Normalization of nerve blood flow and conduction velocity in streptozotocin-diabetic rats treated with guanethidine. Diabetic Medicine 1990; 7 (Suppl 1): 2A.

20. Ward KK, Low PA, Schmelzer JD, Zochodne DW. Prostacyclin and noradrenaline in peripheral nerve of chronic experimental diabetes in rats. Brain 1989; 112: 197-208.
21. Damad Study Group. Effect of aspirin alone and aspirin plus dipyridamole in early diabetic retinopathy. A multicenter randomized controlled clinical trial. Diabetes 1989; 38: 491-498.

22. Parry GJ, Kozu H. Piroxicam may reduce the rate of progression of experimental diabetic neuropathy. Neurology 1990: 40: 14461449.

23. Zochodne DW, Ward KK, Low PA. Guanethidine adrenergic neuropathy: an animal model of selective autonomic neuropathy. Brain Res 1988; 461: 10-16.

24. Low PA, Nukada H, Schmelzer JD. Tuck RR, Dyck PJ. Endoneurial oxygen tension and radial topography in nerve edema. Brain Res 1985; 341: 147-154.

25. Zochodne DW, Ho LT. Influence of perivascular peptides on endoneurial blood flow and microvascular resistance in the sciatic nerve of the rat. J Physiol (London) 1991; 444: 615-630.

26. Rundquist I, Smith QR, Michel ME, Ask P. Oberg PA. et at. Sciatic nerve blood flow measured by laser doppler flowmetry and 14 iodoantipyrine. Am J Physiol 1985; 248: H311-H317.

27. Sladky JT, Greenberg JH, Brown MJ. Regional perfusion in normal and ischemic rat sciatic nerves. Ann Neurol 1985: 17: 191-195.

28. Low PA, Tuck RR. Effects of changes of blood pressure, respiratory acidosis and hypoxia on blood flow in the sciatic nerve of the rat. J Physiol (London) 1984; 347: 513-524.

29. Monafo WW, Eliasson SG, Shimazaki S, Sugimoto H. Regional blood flow in resting and stimulated sciatic nerve of diabetic rats. Exp Neurol 1988; 99: 607-614.

30. Yasuda $H$, Sonobe M, Yamashita M, Terada $M$. et al. Effect of prostaglandin El analogue TFC 612 on diabetic neuropathy in streptozocin-induced diabetic rats. Diabetes 1989; 38: 832-838.

31. Sharma AK, Thomas PK. Peripheral nerve structure and function in experimental diabetes. J Neurol Sci 1974: 23: 1-15.

32. Newrick PG, Wilson AJ, Jakubowski J, Boulton AJM. Ward JD Sural nerve oxygen tension in diabetes. Brit Med J 1986; 293 ; 1053-1054.

33. Pries AR, Ley K, Claassen M, Gaehtgens P. Red cell distribution at microvascular bifurcations. Microvasc Res 1989: 38: 81-101.

34. Simpson LO. Altered blood rheology in the pathogenesis of diabetic and other neuropathies. Muscle Nerve 1988; 11: 725-744

35. Ditzel J. Oxygen transport impairment in diabetes. Diabetes 1976; 25(2): 832-838.

36. Parry GJ, Kohzu H. Studies of resistance to ischemic nerve conduction failure in normal and diabetic rats. J Neurol Sci 1989; 93 $61-67$.

37. Hampton KK, Alani SM, Wilson JI, Price DE. Resistance 10 ischaemic conduction failure in chronic hypoxaemia and diabetes. J Neurol, Neurosurg Psychiatry 1989; 52: 1303-1305.

38. Masson EA, Church SE, Woodcock AA. Hanley SP. Boulton AJM. Is resistance to ischemic conduction failure induced by hypoxia? Diabetologia 1988; 31: 762-765.

39. Dyck PJ. Hypoxic neuropathy: Does hypoxia play a role in diabetic neuropathy? Neurology 1989; 39: 111-118.

40. Johnson EM, Manning PT. Guanethidine-induced destruction of sympathetic neurons. Int Rev of Neurobiol 1984; 25: 1-37.

41. Sharma YR, Cotlier E. Inhibition of lens and cataract aldose reductase by protein-bound anti-rheumatic drugs: salicylate indomethacin, oxyphenbutazone, sulindac. Exp Eye Res 1982: 35: $21-27$

42. Chaudhry PS, Cabrera J, Juliani HR, Varma SD. Inhibition of human lens aldose reductase by flavonoids, sulindac and indomethacin. Biochem Pharmacol 1983; 32: 1995-1998.

43. Tomlinson DR, Moriarty RJ, Mayer JH. Prevention and reversal of defective axonal transport and motor nerve conduction velocity in rats with experimental diabetes by treatment with the aldose reductase inhibitor sorbinil. Diabetes 1984; 33: 470-476.

44. Yue DK, Hanwell MA, Satchell PM, Turtle JR. The effect of aldose reductase inhibition on motor nerve conduction velocity in diabetic rats. Diabetes 1982: 31: 789-794.

45. Sima AAF, Brismar T, Yagihashi S. Neuropathies encountered in the spontaneous diabetic BB wistar rat. $I n$ : Dyck PJ. Thomas PK, Asbury AK, Winegrad Al. Porte D, eds. Diabetic Neuropathy, Toronto: WB Saunders, 1987.

46. Brownlee M, Cerami A. Vlassara $H$. Advanced glycosylation end products in tissue and the biochemical basis of diabetic complications. N Engl J Med 1988; 318: 1315-1321. 